NOTICE: this is the author's version of a work that was accepted for publication in Forensic Science International. Changes resulting from the publishing process, such as peer review, editing, corrections, structural formatting, and other quality control mechanisms may not be reflected in this document. Changes may have been made to this work since it was submitted for publication. A definitive version was subsequently published in Forensic Science International, DOI: 10.1016/j.forsciint.2020.110589. 


\title{
Effect of carrier solvent in 1,2-indanedione formulation on the development of fingermarks on porous substrates
}

\author{
Ya-Bin Zhao ${ }^{1, *}$, Li-Xue Wang ${ }^{1}$, Wen-Jie Li ${ }^{1}$, Wei You ${ }^{1}$, Kevin Farrugia ${ }^{2}$ \\ ${ }^{1}$ Department of Forensic Science, People's Public Security University of China, Beijing \\ 100038, China \\ ${ }^{2}$ Faculty of Health and Life Sciences, Leicester School of Pharmacy, De Montfort University, \\ The Gateway, Leicester, LE1 9BH, UK.
}

* Corresponding author. Tel.:+86 10 83906089(O), E-mail address: zhaoyb04@ gmail.com (Y. B Zhao) 


\begin{abstract}
:
As an important technique for the detection of fingermarks on porous surfaces, 1,2-indanedione is widely used due to its excellent detection performance. In order to optimize the effectiveness of 1,2-indanedione, several institutions have modified the original formulation. In this study, four different 1,2-indanedione formulations were used to treat fingermarks deposited on different porous substrates to determine the most suitable formulation and whether Solstice-PF can be an alternative carrier solvent for the currently used HFE7100. It was found that the Solstice-PF-based formulation performed similarly to the HFE7100based formulation on copy paper, but when treating fingermarks deposited on brown paper and newspaper, Solstice-PF was superior to HFE7100 by developing up to $10 \%$ more marks graded 3 and 4 regardless of the ageing period. The results confirm that Solstice-PF can be used as an alternative carrier solvent for 1,2-indanedione formulations with good detection rates and lower costs.
\end{abstract}

Keywords : fingermark development, formulation comparison, carrier solvent, HFE7100, Solstice-PF 


\section{Introduction}

1,2-Indanedione (IND) is a dual fingerprint reagent that reacts with amino acids to produce both a visual pink colour as well as strong luminescence. IND, compared to ninhydrin and 1,8-diazafluoren-9one (DFO), provides superior results in terms of both the luminescence intensity and detection rates ${ }^{[1-3]}$. The use of IND for the detection of fingermarks on porous surfaces was first reported by scientists at the University of Pennsylvania in $1995^{[4]}$ and quickly became an established amino acid reagent for the detection of fingermarks ${ }^{[5]}$. In addition, IND has the advantages of a relatively simple molecular structure and an easy synthesis route resulting in research efforts for the improvement of this reagent, including molecular structural functionalization ${ }^{[6]}$, formulation and optimization of development conditions ${ }^{[7]}$. By the end of 1990s, a variety of IND derivatives with different substitution groups were synthesized and evaluated as latent fingerprint development reagents by many research groups ${ }^{[8]}$. The results indicated that these compounds possess the advantages of simple preparation, good solubility in nonpolar solvents and high sensitivity to amino acids, which reinforced the knowledge that IND is a practical reagent for the detection of latent fingermarks on porous surfaces.

The success of the IND compounds for the visualization of latent fingermarks resulted in additional work for the formulation optimization of IND as well as the corresponding reaction conditions and influencing factors. Although the results of earlier studies concerning formulation optimization and processing conditions varied from country to country ${ }^{[9,10]}$, these investigations demonstrated a strong link between the fluorescent intensity and the presence of zinc salts and methanol. In 2006, Stoilovic et al. ${ }^{[11]}$ reported that the combination of zinc chloride with the IND reagent produced superior results than DFO and made the effectiveness of IND less vulnerable to the relative humidity of the environment. The research conducted by Roux's group in 2011 confirmed that the zinc (II) ion added in the IND working solution is the key intermediate for catalyzing the Lewis acid and limiting the hydrolysis ${ }^{[12]}$. Meanwhile, the choice of carrier solvent in the amino acid reagent formulation can also play an important role. At first, solvents such as petroleum ether ${ }^{[13]}$, acetone ${ }^{[14]}$, and Freon ${ }^{[15-17]}$ were frequently used in ninhydrin and DFO formulations. These early formulations suffered from several shortcomings including low sensitivity, destruction of the ozone layer, and organic solvents that were often highly flammable. With the implementation of the Montreal Protocol ${ }^{[15]}$, CFCs have been phased out due to environmental concerns. Other studies have assessed possible alternative carrier solvents such as Genesolv2020 ${ }^{[18]}$, Genesolv2000 ${ }^{[19]}$ and HFC 4311 mee $^{[20]}$. A major research project which recommended the use of HFE7100 as an alternative carrier solvent to Freon in formulations for latent fingermark detection was carried out by Gardner and Hewlett ${ }^{[7]}$ in 2003. However, HFE7100 still has the disadvantages of environmental pollution and high cost though it is relatively safe and effective ${ }^{[21]}$. HFE7100 is also currently under a consideration ban within the $\mathrm{EU}^{[22]}$. Therefore, an alternative carrier solvent with suitable properties is desirable. In 2015, Honeywell developed a new low global warming potential (GWP) solvent, Solstice-PF (trans-1-chloro-3,3,3-trifluoropropene), which can replace the high GWP solvent HFE7100 currently used for formulations of amino acid reagents. Subsequently, Farrugia's group proposed that Solstice-PF could be used as an alternative carrier solvent for HFE7100 to develop latent fingerprints ${ }^{[21]}$. Compared to HFE7100, Solstice-PF persists for less time in the environment and also has lower costs and a GWP of 1 (Table 1). Hence, it is worthwhile to evaluate the performance of different IND formulations with Solstice-PF as an alternative to HFE7100. 
Table 1. Chemical properties of HFE7100 and Solstice $\mathrm{PF}^{[23]}$

\begin{tabular}{|c|c|c|c|c|c|}
\hline Name & Chemical name & Molecular Fomula & Boiling point $\left({ }^{\circ} \mathrm{C}\right)$ & GWP & Price \\
\hline HFE7100 & $\begin{array}{c}\text { methyl nonafluorobutyl ether(1- } \\
\text { methoxynonafluorobutane) }\end{array}$ & $\mathrm{C}_{5} \mathrm{H}_{3} \mathrm{~F}_{9} \mathrm{O}$ & 61 & 320 & $¥ 530 / \mathrm{kg}$ \\
\hline Solstice PF & trans-1-chloro-3,3,3-trifluoropropene & $\mathrm{CF}_{3}-\mathrm{CH}=\mathrm{CCIH}$ & 19 & 1 & $¥ 260 / \mathrm{kg}$ \\
\hline
\end{tabular}

This paper intends to compare four widely used formulations of IND, then explore whether SolsticePF can be applied as an alternative carrier solvent to HFE7100 for the most effective formulation. Four commonly used IND formulations from the Home Office CAST in 2011 (CAST 2011), the University of Lausanne (UL), the University of Technology Sydney (UTS), and the modified Home Office CAST 2014(hereinafter referred to as the CAST 2014*) ${ }^{[24]}$ were assessed in the first stage of the study to evaluate their performance of developing fingermarks on copy paper, brown paper and newspaper. The most effective formulation was then further assessed with Solstice-PF and HFE7100 as carrier solvents.

\section{Materials and Methods}

\subsection{Chemicals and Instruments}

1,2-indanedione was purchased from KeFeng Co, Ltd (Shanghai, China). Ethyl acetate, zinc chloride, methanol and acetic acid were all purchased from Beijing Chemical Works (Beijing, China). HFE 7100 was purchased from Goforward (Shenzhen, China). Solstice-PF was obtained from Honeywell International Inc. (Shanghai, China). A Jing Hong XMTD-8222 Dry oven was obtained from Jing Hong Technology Co. Ltd (Shanghai, China). All chemicals were used without further purification.

\subsection{Sample preparation}

The study used seven donors (four males and three females) for the deposition of natural fingermarks and these were prepared as recommended by the IFRG guidelines ${ }^{[25]}$.

Samples for Formulation comparison: Each donor was asked to leave five fingermarks under natural conditions on three different paper types, i.e. copy paper, brown paper and newspaper (Fig. 1a), following the 'quartered fingermark' method ${ }^{[26]}$. A single fingermark was deposited at the center of the paper and other marks were deposited across the centerline of each quarter. Different sets of fingermarks were aged for intervals of 1, 7, 15 and 30 days before processing. Each set of fingermarks on different substrate was cut along the horizontal and vertical central axis into four quarters, and treated with four different formulations of IND reagent separately. Then, the processed quarters were re-combined for scoring and further comparison.

Samples for comparison of HFE7100 with Solstice-PF: Four depletion series of fingermarks from four different fingers were deposited on the substrates, and this process was repeated by each donor on copy paper, brown paper and newspaper. (Fig. 1b). Each depletion series contained five continuous depositions. Different sets of fingermarks were aged for 1, 7, 15, and 30 days before processing. Each fingermark was cut into half along the centerline, and each cut section was treated with the HEF7100based and the Solstice-PF-based IND formulations separately. Then, the processed halves were recombined for scoring and further comparison. 


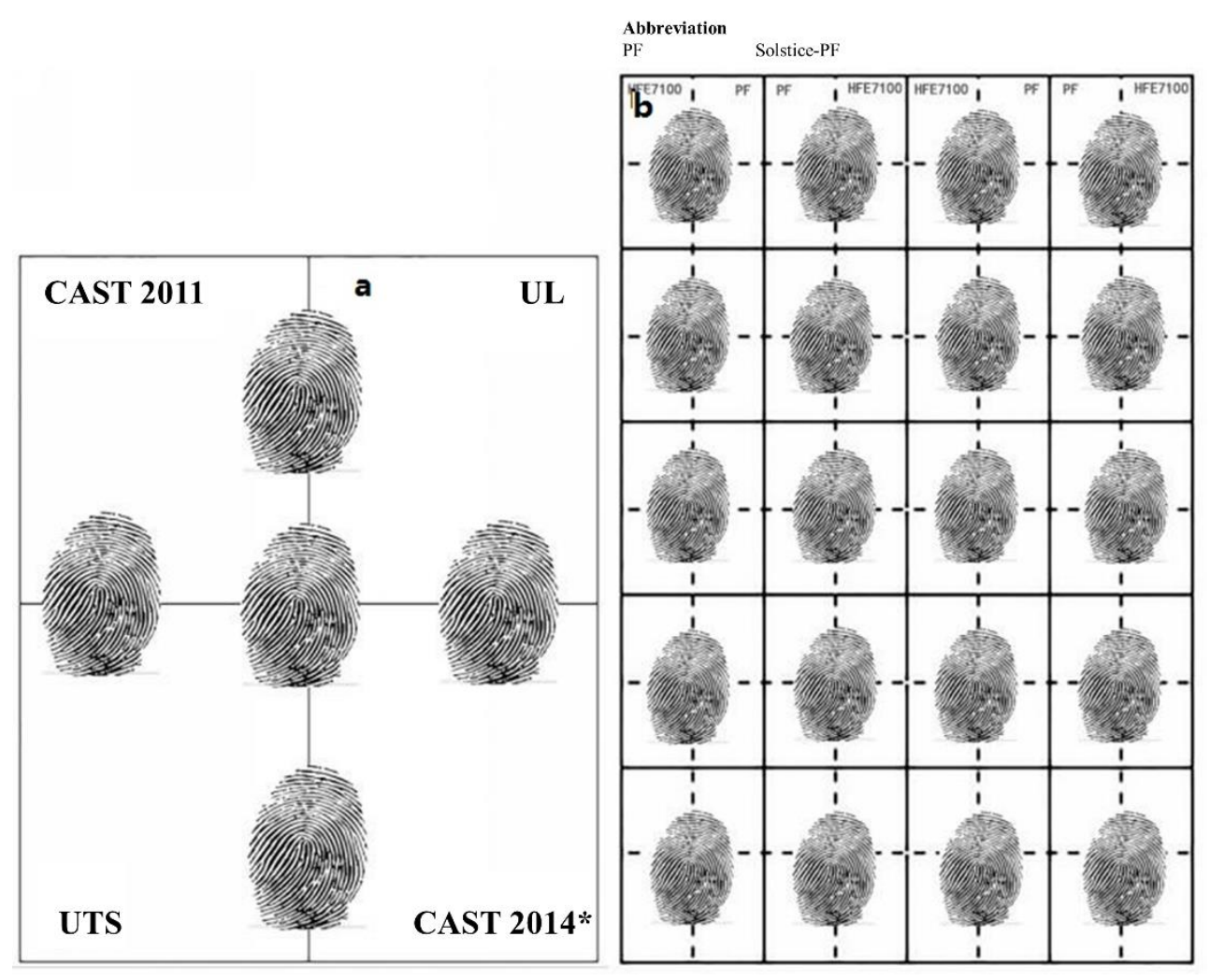

Fig. 1. Schemes of sample deposition in this study ${ }^{[26]}$

\subsection{IND Formulations}

The IND formulations involved in the studies are summarized in Table 2. The CAST 2011, UL, UTS and the CAST $2014 *$ formulations were used in the formulation comparison study, while the CAST 2014* and the Solstice-PF formulations were used in the carrier solvent comparison study ${ }^{[21]}$.

\subsection{Development and recording of fingermarks}

During preliminary trials, two heating methods (an oven at $100^{\circ} \mathrm{C}$ for 10 minutes ${ }^{[27]}$ and a heat press set at $165^{\circ} \mathrm{C}$ for $10 \mathrm{~s}^{[28]}$ ) widely recommended for IND formulations were evaluated. The use of an oven provided developed fingermarks with better ridge detail and was therefore used for the development of IND treated fingermarks in this study. The split samples left on different types of papers were soaked in the corresponding reagents and dried, then heated in the dry oven at $100^{\circ} \mathrm{C}$ for 10 minutes. Developed samples were recombined according to the original position. Examinations in the fluorescence mode were then carried out with a Poliview (530 nm excitation and observed with a $580 \mathrm{~nm}$ filter). All the

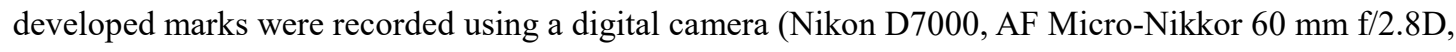
Japan). 
Table 2. IND formulations used in the experiment. ${ }^{\mathrm{a}, \mathrm{b}}$

\begin{tabular}{|c|c|c|c|}
\hline 1,2-indanedione formulation & Composition & Zinc stock composition & Solvent \\
\hline CAST $2011^{[24]}$ & $\begin{array}{l}0.25 \mathrm{~g} 1,2 \text {-indanedione } \\
90 \mathrm{ml} \text { ethyl acetate } \\
10 \mathrm{ml} \text { acetic acid } \\
1 \mathrm{ml} \text { zinc stock }\end{array}$ & $\begin{array}{l}0.1 \mathrm{~g} \text { zinc chloride } \\
4 \mathrm{ml} \text { ethyl acetate } \\
1 \mathrm{ml} \text { acetic acid }\end{array}$ & 1L HFE7100 \\
\hline $\mathrm{UL}^{[24]}$ & $\begin{array}{l}0.25 \mathrm{~g} 1,2 \text {-indanedione } \\
100 \mathrm{ml} \text { ethyl acetate } \\
10 \mathrm{ml} \text { acetic acid } \\
100 \mathrm{ml} \text { methanol } \\
20 \mathrm{ml} \text { zinc stock }\end{array}$ & $\begin{array}{l}0.2 \mathrm{~g} \text { zinc chloride } \\
0.5 \mathrm{ml} \text { ethyl acetate } \\
5 \mathrm{ml} \text { methanol } \\
95 \mathrm{ml} \text { HFE7100 }\end{array}$ & 800ml HFE7100 \\
\hline $\mathrm{UTS}^{[24]}$ & $\begin{array}{l}0.25 \mathrm{~g} 1,2 \text {-indanedione } \\
90 \mathrm{ml} \text { ethyl acetate } \\
10 \mathrm{ml} \text { acetic acid } \\
4 \mathrm{ml} \text { zinc stock }\end{array}$ & $\begin{array}{l}8 \mathrm{~g} \text { zinc chloride } \\
200 \mathrm{ml} \text { methanol }\end{array}$ & 900ml HFE7100 \\
\hline CAST $2014^{*[24]}$ & $\begin{array}{l}0.25 \mathrm{~g} 1,2 \text {-indanedione } \\
45 \mathrm{ml} \text { ethyl acetate } \\
45 \mathrm{ml} \text { methanol } \\
10 \mathrm{ml} \text { acetic acid } \\
1 \mathrm{ml} \text { zinc stock }\end{array}$ & $\begin{array}{l}0.1 \mathrm{~g} \text { zinc chloride } \\
4 \mathrm{ml} \text { ethyl acetate } \\
1 \mathrm{ml} \text { acetic acid }\end{array}$ & 1L HFE7100 \\
\hline Solstice-PF ${ }^{[21]}$ & $\begin{array}{l}0.25 \mathrm{~g} 1,2 \text {-indanedione } \\
45 \mathrm{ml} \text { ethyl acetate } \\
45 \mathrm{ml} \text { methanol } \\
10 \mathrm{ml} \text { acetic acid } \\
1 \mathrm{ml} \text { zinc stock }\end{array}$ & $\begin{array}{l}0.1 \mathrm{~g} \text { zinc chloride } \\
4 \mathrm{ml} \text { ethyl acetate } \\
1 \mathrm{ml} \text { acetic acid }\end{array}$ & 1L Solstice-PF \\
\hline
\end{tabular}

${ }^{\mathrm{a}}$ Each reagent should be added in order and fully dissolved and the reagents should be prepared right before they will be used to avoid the volatilization of solvent.

${ }^{\mathrm{b}}$ With a boiling point of only $19^{\circ} \mathrm{C}$, unsealed Solstice-PF reagent is recommended to be preserved in the fridge.

\subsection{Assessment of developed fingermarks}

Developed marks were scored according to a quantitative scale recommended by the UK Home Office (Table3). In addition to this absolute quantitative scale, the fingermarks treated with different reagents were also assessed quantitatively by the relative fluorescence intensity. Areas of the same size were chosen from the developed fingermarks images for fluorescence measurement by the imaging processing program Image $\mathrm{J}$ through a methodology proposed for anatomical research ${ }^{[29]}$. To quantitatively represent the fluorescence intensity of the detected fingermarks under $530 \mathrm{~nm}$ excitation, the mean fluorescence intensity (MFI), which is defined as the fluorescence intensity per square millimeter area, was used in this study.

Table 3. Quantitative scale used to describe the development results of the fingermarks in this study ${ }^{[26]}$

\begin{tabular}{cc}
\hline Score & Description \\
\hline 0 & No evidence of mark \\
2 & Weak development with little evidence but no ridge detail \\
3 & Strong development with $1 / 3$ to $2 / 3$ ridge details occurred, which is identifiable \\
4 & Very strong development with full ridge details make the mark identifiable
\end{tabular}




\section{Results and discussion}

\subsection{Comparison of the IND formulations}

Fig. 2a shows an image of a typical set of quartered fingermarks. The fingermarks left on the three different types of papers were quartered and treated with the CAST 2011, UL, UTS and CAST 2014* IND formulation separately. It is clearly observed that on all kinds of substrates, the quartered fingermarks developed with the UL and CAST 2014* formulations had better quality in both the clarity of ridges and fluorescence intensity compared with fingermarks processed with UTS and CAST 2011 formulations (Fig. 2b). This result may be attributed to the present of relatively large amounts of methanol in the UL and CAST 2014* formulations. The use of methanol in the IND formulation is described in other studies as important for producing marks with the highest fluorescence intensity ${ }^{[24]}$. The fluorescence intensity for the UL formulation was higher than the CAST 2014*; however, CAST 2014* seemed to produce continuous ridges and sharpened fingermark images with better contrast and more detail.

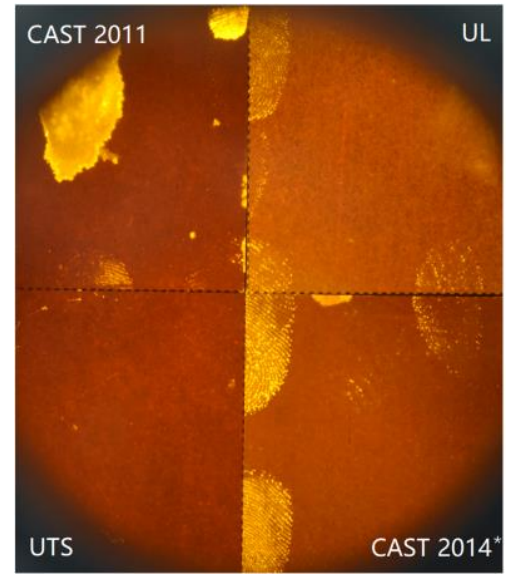

Fig. 2a. An example of fingermarks developed on copy paper using the 'quartered fingermark’ method.
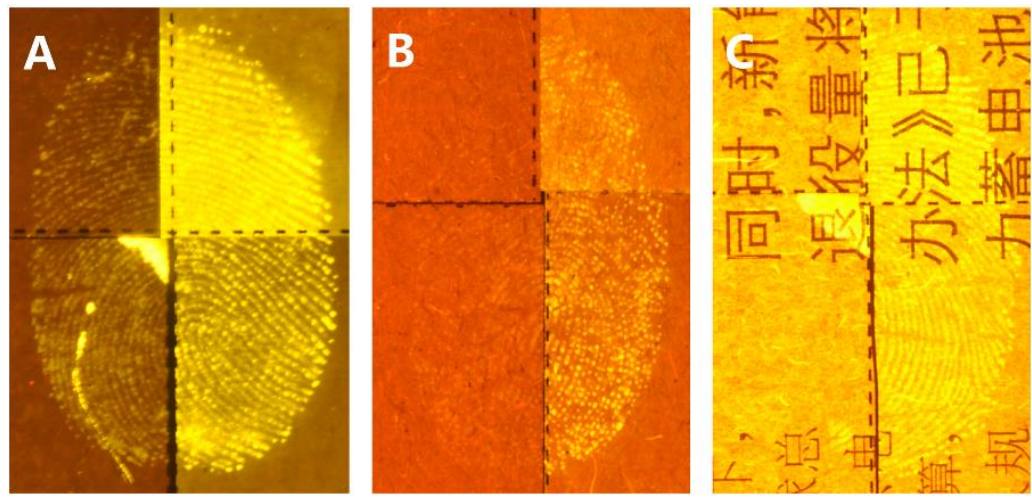

Fig. 2b. Latent fingermarks developed with four IND formulations showing ridge details on copy paper (A), brown paper (B), and newspaper (C)

Fig. 3 displays the distribution of grades for all donors and ageing periods by different IND formulations and substrates. It can be seen from the results that the CAST 2014* formulation provided the best results overall especially on brown paper and newspaper whereas the CAST 2011 gave the poorest results. The UL formulation also outperformed the UTS formulation when taking into account the marks with high quality scores (3 and 4) on the three different paper substrates (Fig. 3a). To evaluate 
the sensitivity of the four formulations, fingermarks aged for different time periods but grouped by all three substrates were processed and scored as demonstrated in Fig. 3b. It was also observed that the CAST 2014* formulation showed similar and better enhancement results across all ageing periods. There is a decrease in the number of fingermarks graded 3 and 4 as the ageing period increases; however, there is still a 70\% detection rate for fingermarks aged for 30 days. The CAST 2011 and UTS formulations performed unsatisfactorily even for fingermarks aged for one day, and failed to detect most of the fingermarks (graded 3 and 4) when aged for 15 days or longer. The result confirmed that the CAST 2014* formulation gives the best performance on all paper types and different age intervals under the operational condition (heated in the dry oven at $100^{\circ} \mathrm{C}$ for 10 minutes) chosen in this study.

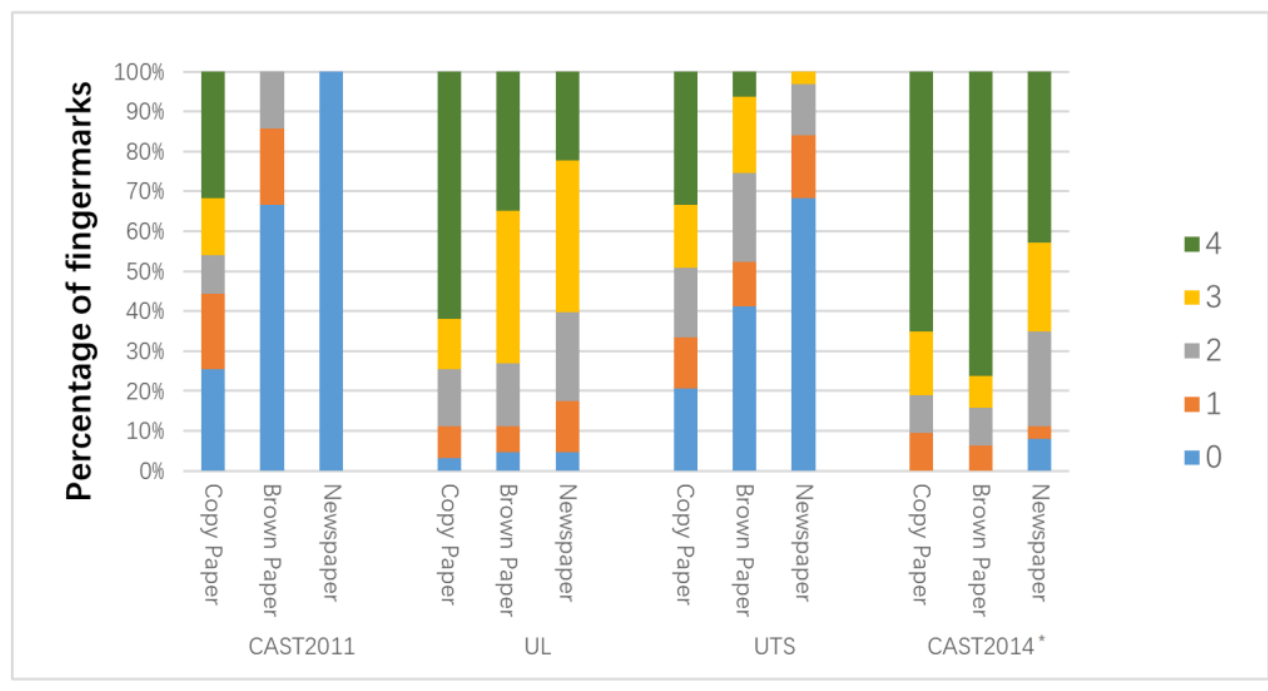

Fig. 3a. Distribution of the grades of fingermarks processed by different formulations on three types of papers.

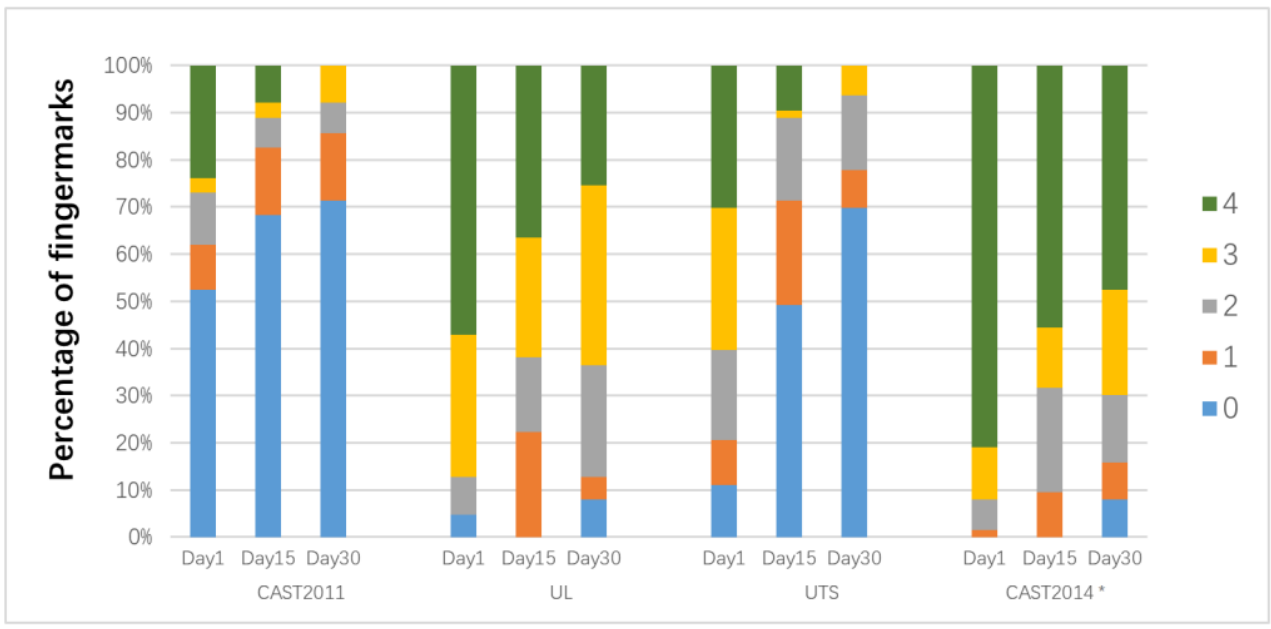

Fig. 3b. The overall grades of fingermarks aged for different time intervals and processed by different formulations on three types of papers.

In order to evaluate the effectiveness from the prospective of fluorescence intensity, the MFI value of all fingermarks developed by the four different formulations were measured and calculated as an average based on different substrates or different age period (Fig.4). Fig.4a illustrates the average MFI of developed fingermarks on copy paper, brown paper and newspaper. It is clear that the fingermarks developed with the UL formulation gave the highest MFI on three substrates, while CAST 2014* gave 
the second highest MFI. Fig.4b is the average MFI of fingermarks on three types of paper across the different ageing periods. The MFI results observed across the different ageing periods was similar to that observed across the three different substrates. The highest MFI, however, was not seen in fingermarks aged for one day as expected. For UL and CAST2011, the fluorescence intensity remained constant over the three ageing periods up to 30 days. Meanwhile, the MFI for the UTS formulation reached a maximum at an ageing period for 15 days before dropping back to the initial levels.

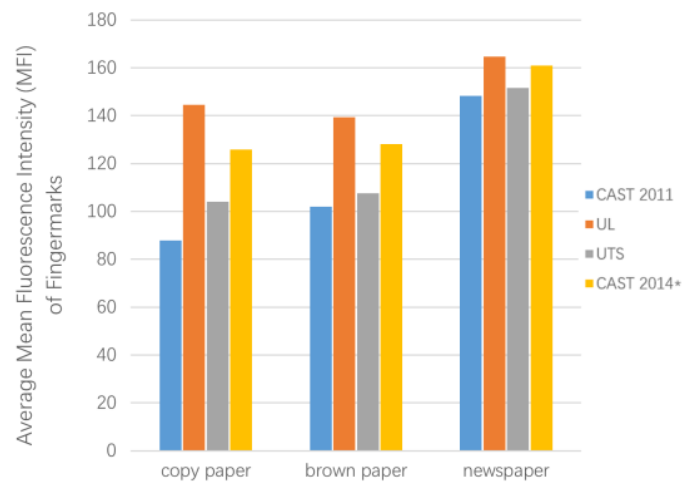

(a)

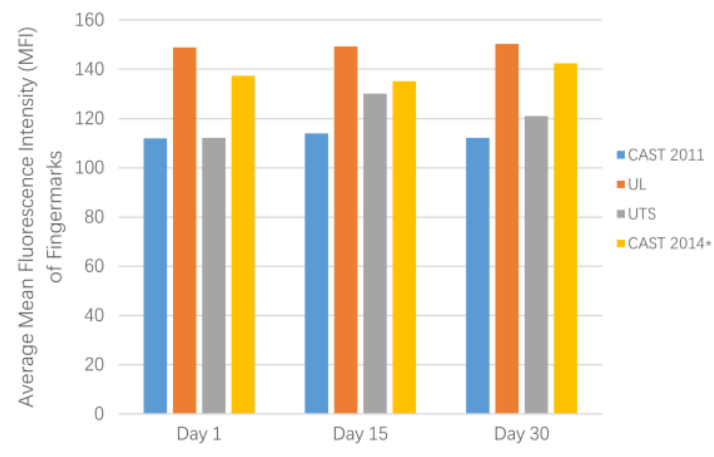

(b)

Fig. 4. Average mean fluorescence intensities (MFI) of fingermarks treated with four different IND formulations across three different substrates (a) and across different ageing periods (b).

The CAST 2014* formulation performed the best amongst the four different formulations of IND when considering the quality of the marks developed, the MFI and the background contrast. This formulation was then selected for the next stage of research in finding the optimal IND carrier solvent for developing latent fingermarks on porous substrates.

\subsection{Carrier solvent comparison of HFE7100 with Solstice-PF for the IND CAST 2014* formulation}

Fig. 5 is a typical illustration of latent fingermarks on different substrates treated with two different carrier solvents. The use of Solstice-PF as a carrier solvent for IND not only resulted in clearer ridges, but also in better background contrast and a higher MFI. The scoring of marks across the three different substrates and two carrier solvents is presented in Fig. 6. It can be seen that the best overall performance was achieved on copy paper with similar results for both formulations. Despite the overall decline in the number of fingermarks graded 3 and 4 on brown paper, Solstice-PF-based and HFE7100-based formulations yielded $54 \%$ and $45 \%$ of these identifiable marks respectively. Due to the background interference of newspapers, the quality of the developed fingermarks on this substrate was poor for both formulations. Overall, both formulations provided similar results although Solstice-PF had a higher number of marks graded 3 and 4 .
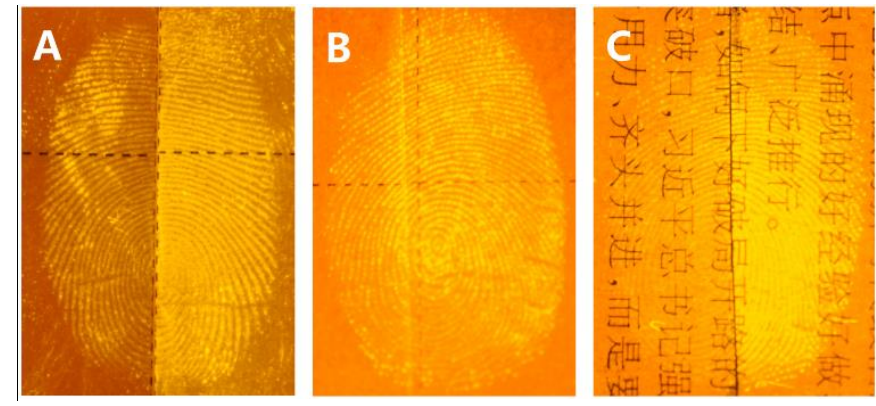

Fig.5 Split latent fingermarks on (A) Copy paper, (B) Brown paper, (C) Newspaper developed with HFE7100-based (left) and Solstice-PF-based IND formulation (right). 


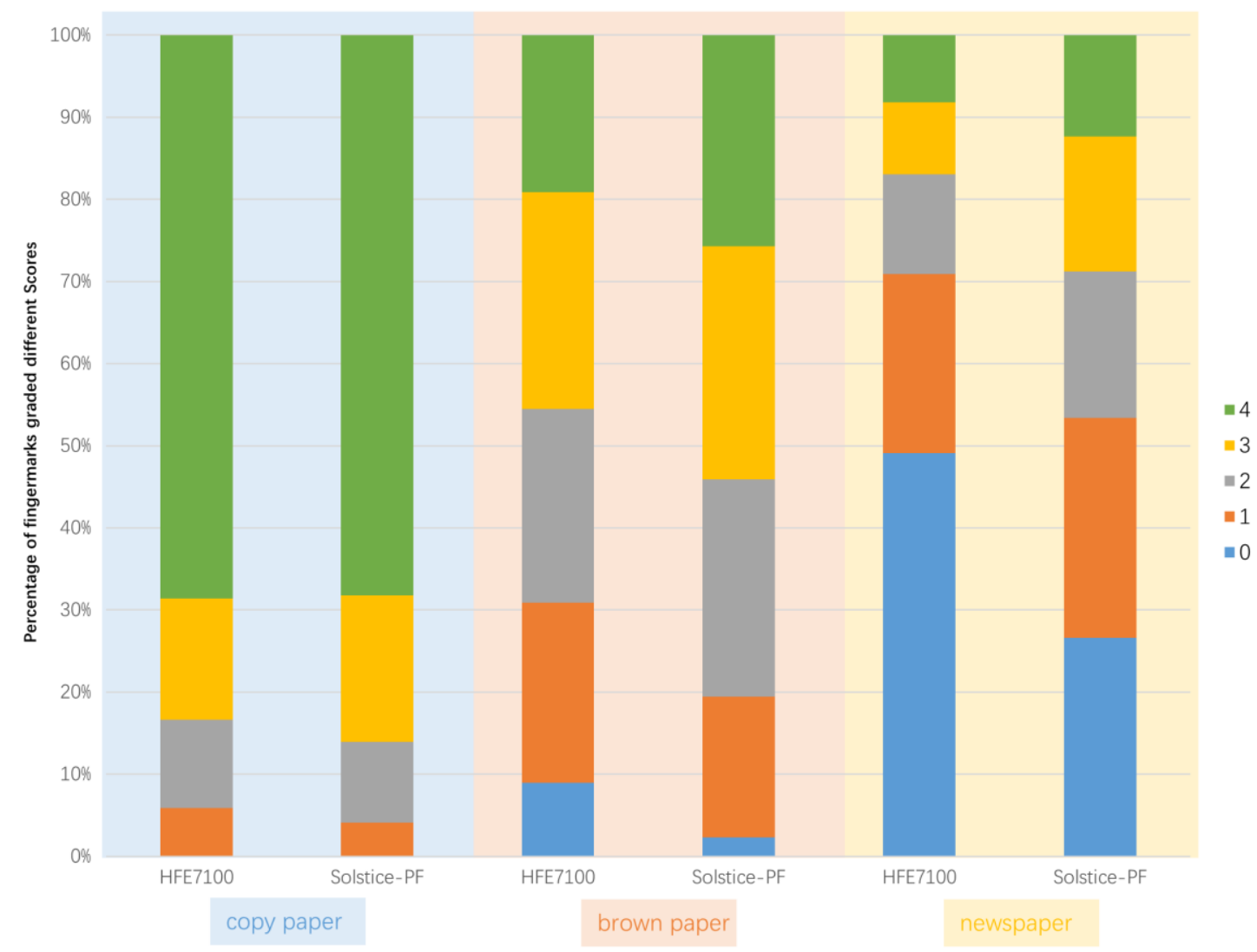

Fig. 6. Distribution of fingermark grades developed by HFE7100 and Solstice-PF-based IND formulations on different substrates.

To test the sensitivity of the two formulations, an additional comparison was carried with depletion series on all three kinds of papers. Fig. 7 shows the development of two depletion series each consisting of five fingermarks aged for seven days. Although the quality and fluorescence intensity decreased down the depletion series, both formulations still provided clear ridge detail for the fifth depletion (Fig. 7E). Both formulations performed similarly and the Solstice-PF-based IND formulation provided a higher MFI.
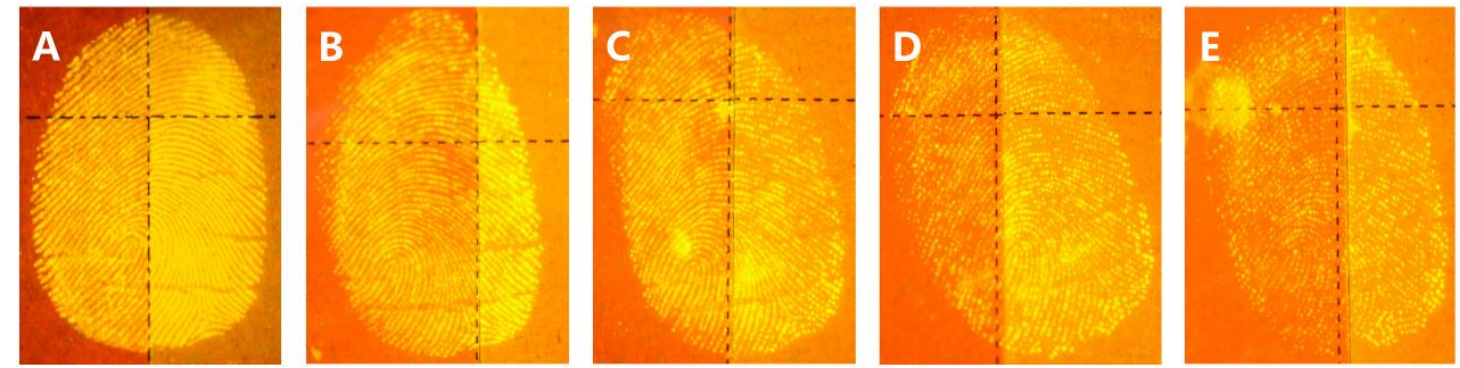

Fig. 7. A depletion series of fingermarks (from left to right) on copy paper aged for seven days treated with HFE7100-based (left) and Solstice-PF-based IND formulations (right).

According to the quality scores of 1680 compared fingermarks across three substrates, it was observed that the Solstice-PF-based formulation is superior to the HFE7100 in terms of the number and quality of fingermarks detected. The study conducted on depletion series suggested that the Solstice-PF had a higher sensitivity. On copy paper, for the fifth depletion, the Solstice-PF-based formulation 
produced about 5\% more fingermarks graded at 3 or 4 when compared to the HFE7100-based formulation (Fig. 8a). On brown paper, both carrier solvent formulations followed the same trends. For both formulations, the percentage of marks scored 2 and above dropped $30 \%$ from the first depletion to the fifth, but the Solstice-PF formulation was approximately $10 \%$ better than the HFE7100 formulation.

(Fig. 8b). The newspaper shared a similar result to the brown paper with respect to the effectiveness of the two formulations (Fig. 8c).

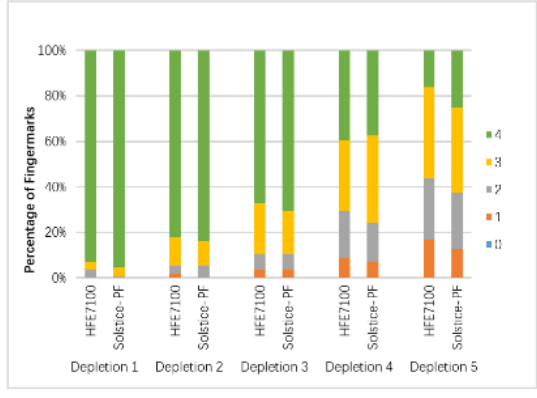

(a)

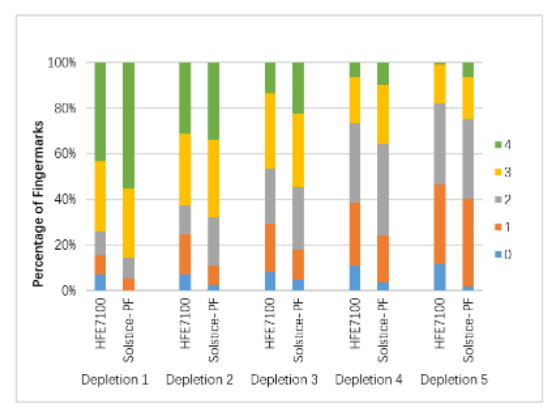

(b)

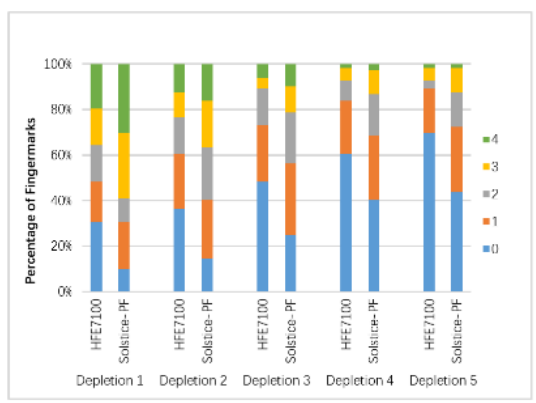

(c)

Fig.8. Comparison of the two formulations for depletion marks on copy paper (a), brown paper (b), and newspaper (c).

Furthermore, fingermarks aged for different time intervals were used to assess how the effectiveness of two formulations changed across different ageing periods. Fig. 9 shows split fingermarks deposited on copy paper, aged for 1, 7, 15, 30 days and developed by HFE7100-based and Solstice-PF-based IND formulations.
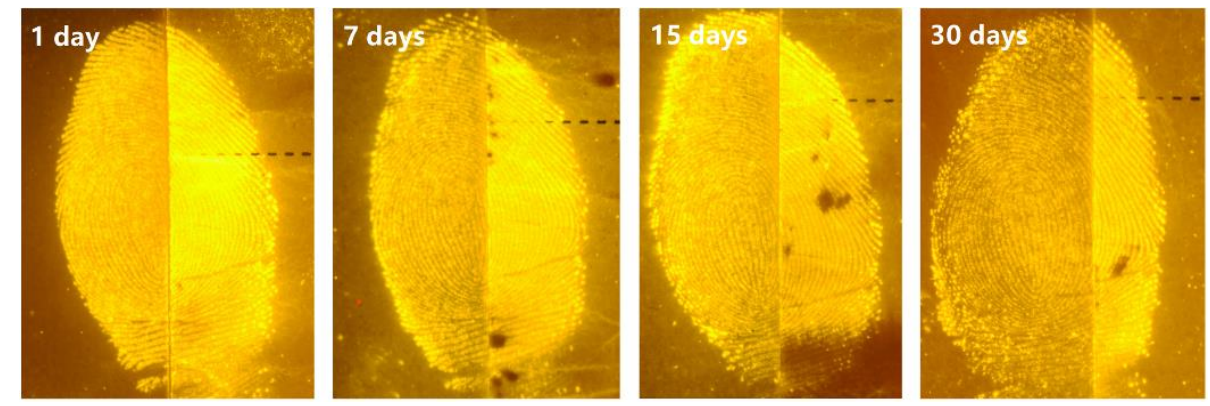

Fig.9. Typical images of fingermarks on copy paper aged for (left to right): 1 day, 7 days, 15 days, and 30 days, treated with HFE7100-based (left) and Solstice-PF-based (right) IND formulations.

Fingermarks detected on the three paper types were graded and sorted according to their age in Fig. 10. The results indicated the effectiveness of the two formulations on copy paper and the percentage of fingermarks scored 3 and 4 only dropped about $8 \%$ from 1 day to 30 days ageing (Fig.10a). On brown papers, Solstice-PF-based formulation outperformed HFE7100-based formulation with 20\% more marks graded 3 and 4 for the 1 and 30 day ageing period; however, the grading for both formulations was similar for marks aged 7 and 15 days. The number of fingermarks developed by HFE7100-based formulation scored 2 and above decreased 35\% from 1 day to 30 days ageing, whereas the Solstice-PF formulation decreased by $21 \%$. For newspapers, the difference in number of marks graded 2 to 4 between the SolsticePF and HFE7100-based formulations was about 15\% for ageing periods for 1, 15 and 30 days. There was no difference for the 7 day ageing period. In general, although the percentage of marks graded 2 to 4 decreased with the increasing ageing period, the decrease was less pronounced for Solstice-PF. 


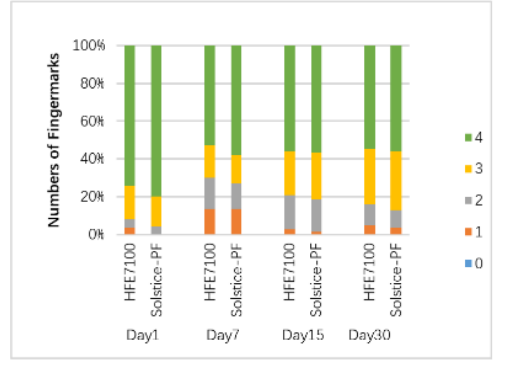

(a)

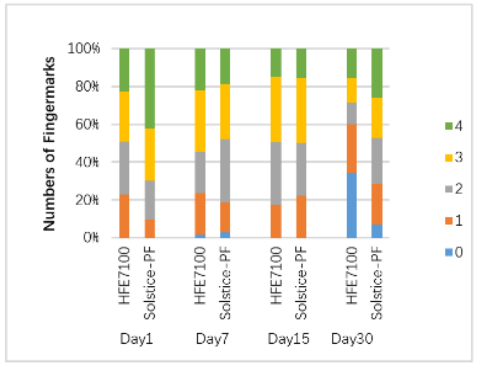

(b)

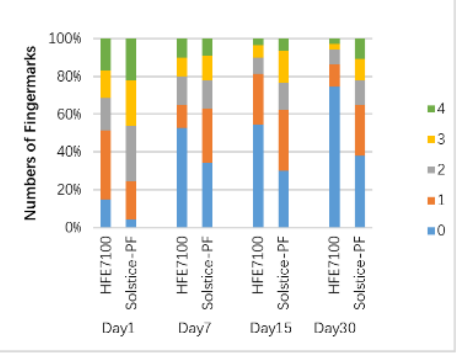

(c)

Fig. 10. Average assessment rates of fingermarks aged for different time intervals on copy paper (a), brown paper (b), and newspaper (c).

Fig.11 lists the average MFI of developed marks calculated by measuring the first mark of all depletions deposited by seven donors on three types of papers (252 fingermarks in total). It is clear that the MFI of fingermarks treated with the Solstice-PF-based formulation were generally higher than those treated with HFE7100-based ones on copy paper, but for the other two substrates, brown paper and newspaper, the results are very similar. For newspapers, the colour and printed words on the background may have affected the results. The results show that Solstice-PF is a possible suitable alternative to HFE7100 as a carrier solvent for this IND formulation.

Average Mean Fluorescence Intensity (MFI) of Fingermarks

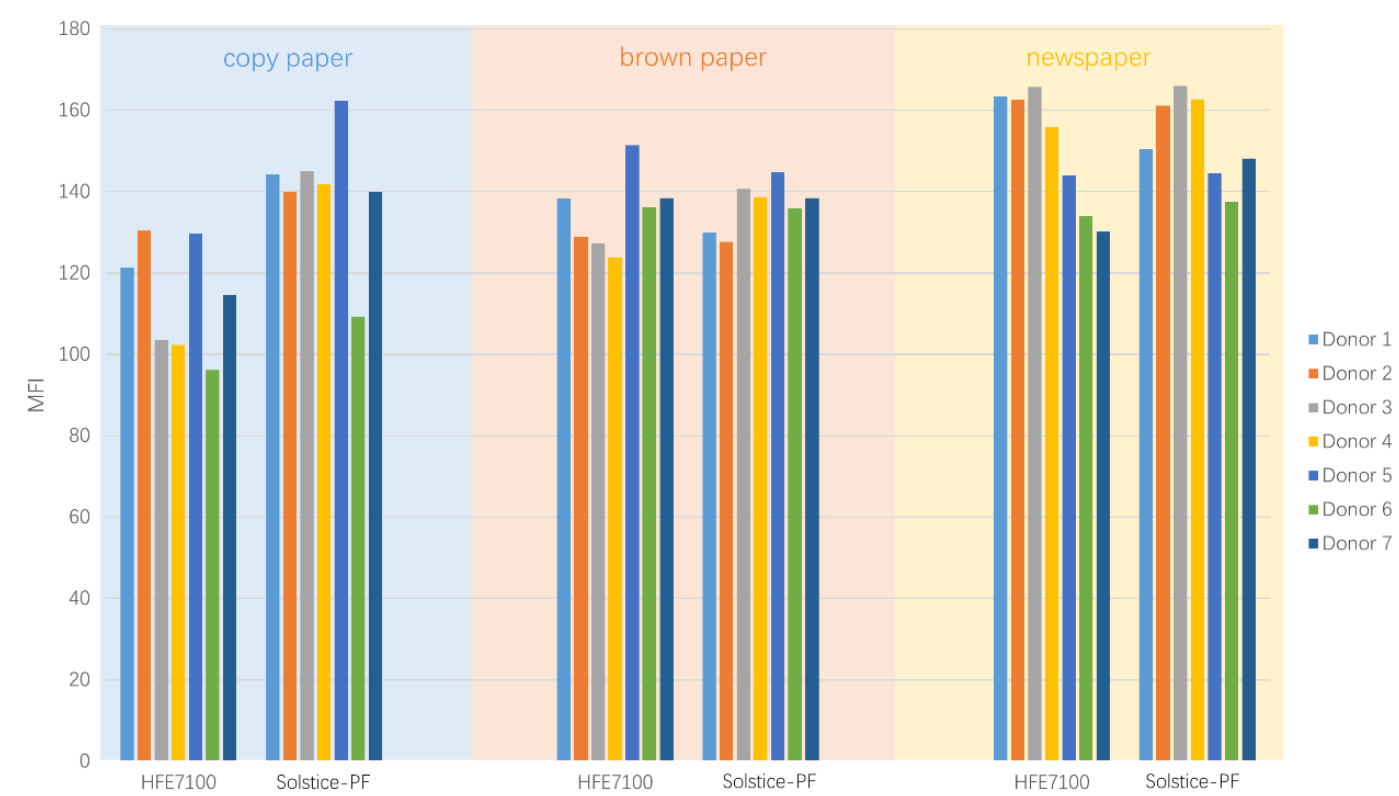

Fig.11. Average mean fluorescence intensities of fingermarks deposited by seven donors on copy paper (left), brown paper (middle), and newspaper (right), treated with the two formulations.

Compared with previous work, this study reconfirmed the results of research by Nicolasora et al. ${ }^{[24]}$ that the CAST 2014* formula is the most effective formulation under the described conditions $\left(100^{\circ} \mathrm{C}\right.$ for 10 minutes). The slightly better effectiveness of the Solstice-PF compared to HFE-7100 also supported the study by Olszowska et al. ${ }^{[21]}$ and that Solstice-PF can be an appropriate alternative carrier solvent for IND. Compared to these previous studies, the use of the MFI value introduced in this study provides a different perspective for evaluating the performance Solstice-PF and HFE-7100. Nonetheless, further research is required in this area, for example the need to eliminate the background influence when calculating the MFI value of the fingermarks. 


\section{Conclusion}

As a technique for the detection of latent fingermarks on porous surfaces, IND has been a research hotspot since its introduction in the 1990s. Over the years, many studies have improved the effectiveness of the IND formulation. This study investigated the use of IND for the detection of latent fingermarks on copy paper, brown paper and newspaper in China. Systematic evaluation of four different IND formulations was performed to compare their efficacy in developing latent fingermarks. The result of the initial study indicated that CAST 2014* was the optimal formulation, based upon which the use of Solstice-PF and HFE7100 as carrier solvents was further explored. The study concluded that the Solstice$\mathrm{PF}$ formulation for IND is at least as effective as the HFE7100-based formulation. For marks graded 3 and 4 , the Solstice-PF based formulation detected approximately $2 \%$ more marks on copy paper and about $10 \%$ more on both brown paper and newspaper. The study confirmed that Solstice-PF, which has lower costs and a GWP of 1, can be an alternative carrier solvent to HFE7100 for IND formulations. Further studies on additional different porous substrates in addition to pseudo and full operational trails will be investigated in future work. 


\section{Acknowledgment}

We gratefully thank the Honeywell International Inc. (Shanghai, China) for providing the Solstice PF reagent. This work was supported by the Fundamental Research Funds for the Central Universities in China (2019JKF216) and Public Security Behavioural Science Research and Technological Innovation, People's Public Security University of China. 


\section{References}

[1] M. Levin-Elad, Y. Liptz, K.L. Bar-Or, J. Almog, 1,2-Indanedione - A winning ticket for developing fingermarks: A validation study, Forensic Sci. Int. 271 (2017) 8-12.

[2] A. Luscombe, V. Sears, A Validation Study of the 1,2-Indandione Reagent for Operational Use in the UK: Part 3-Laboratory Comparison and Pseudo-Operational Trials on Porous Items, Forensic Sci. Int. 292 (2018) 254-261. [3] C.N. Loh, W.L.K. Chia, S.C.S. Foo, X. Xu, W.L.S. Tan, Evaluation of the performance of IND/Zn and DFO on various porous substrates in Singapore context, Forensic Sci. Int. 315 (2020) 110440

[4] R. Ramotowski, A.A. Cantu, M.M. Joullie, O. Petrovskaia, 1,2-Indanediones: a preliminary evaluation of a new class of amino acid visualising reagents, Fingerprint Whorld, 90 (1997) 131-140.

[5] C. Roux, N. Jones, C. Lennard. Evaluation of 1,2-indanedione and 6-dimethoxy-1,2-indanedione for the detection of latent fingerprints on porous surfaces. J. Forensic Sci. 45(4) (2000) 761-769.

[6] Petrovskaia, B. Taylor, D. Hauze, P. Carroll, M. Joullie, Investigations of the reaction mechanisms of 1,2indanediones with amino acids, J. Org. Chem. 66 (23) (2001) 7666-7675.

[7] S.J. Gardner, D.F. Hewlett, Optimisation and initial evaluation of 1,2-indandione as a reagent for fingerprint detection, J. Forensic Sci. 48 (6) (2003) 1288-1292.

[8] J. Almog, E. Springer, S. Wiesner, A. Frank, O. Khodzhaev, R. Lidor, E. Bahar, H. Varkony, S. Dayan, S. Rozen, Latent fingerprint visualization by 1,2-indandione and related compounds: preliminary results, J. Forensic Sci. 44 (1) (1999) 114-118.

[9] X. Spindler, R. Shimmon, C. Roux, C. Lennard, The effect of zinc chloride, humidity and the substrate on the reaction of 1,2-indanedione-zinc with amino acids in latent fingermark secretions, Forensic Sci. Int. 212 (2011) 150157.

[10] S. Merrick, S.J. Gardner, V.G. Sears, D.F. Hewlett, An operational trial of ozone-friendly DFO and 1,2indandione formulations for latent fingerprint detection, J. Forensic Ident. 52 (2002) 595-605.

[11] M. Stoilovic, C. Lennard, C. Wallace-Kunkel, C. Roux, Evaluation of a 1,2-indanedione formulation containing zinc chloride for improved fingermark detection on paper, J. Forensic Ident. 57(1) (2007) 4-18.

[12] X. Spindler, R. Shimmon, C. Roux, C. Lennard, The effect of zinc chloride, humidity and the substrate on the reaction of 1,2-indanedione-zinc with amino acids in latent fingermark secretions, Forensic Sci. Int. 212 (1-3) (2011) 150-157.

[13] D.A. Crown, The Development of Latent Fingerprints with Ninhydrin, J. Crim. Law, Criminol. Police Sci. 60 (1969) 258-264.

[14] S. Oden, B. von Hofsten, Detection of Fingerprints by the Ninhydrin Reaction, Nature. 173 (1954) 449-450.

[15] D.F. Hewlett, V.G. Sears, Replacements for CFC113 in the Ninhydrin Process: Part 1, J. Forensic Ident. 47 (1997) 287-299.

[16] D.F. Hewlett, V.G. Sears, S. Suzuki, Replacements for CFC113 in the Ninhydrin Process: Part 2, J. Forensic Ident. 47 (1997) 300-331.

[17] D.F. Hewlett, V.G. Sears, An Operational Trial of Two Non-ozone Depleting Ninhydrin Formulations for Latent Fingerprint Detection, J. Forensic Ident. 49 (1999) 388-396.

[18] W. O. Jungbluth, Replacement for Freon 113, Fingerprint Whorld, 18(67) (1992) 26-29.

[19] W. O.Jungbluth, Replacement for Freon 113, J. Forensic Ident. 43 (1993) 226-233.

[20] T. Kent, Two new solvents for ninhydrin, Fingerprint Whorld, 22(85) (1996) 108.

[21] I. Olszowska, P. Deacon, M. Lindsay, et al. An alternative carrier solvent for fingermark enhancement reagents, Forensic Sci. Int. 284 (2018) 53-64.

[22] Regulation (EU) No 517/2014, Regulation (EU) No 517/2014 of the European Parliament and of the Council of 16 April 2014 on fluorinated greenhouse gases and repealing Regulation (EC) No 842/2006, Off. J. Eur. Union 
(2014) L 150 195-230.

[23] C. Champod, C. Lennard, P. Margot, M. Stoilovic. Fingerprints and Other Ridge Skin Impressions (2nd ed.). CRC Press, 2016.

[24] N. Nicolasora, R. Downham, Laura. Hussey, et al. A validation study of the 1,2-indandione reagent for operational use in the UK: Part 1-Formulation optimization, Forensic Sci. Int. 292 (2018) 242-253.

[25] IFRG, Guidelines for the assessment of fingermark detection techniques, J. Forensic Ident. 64(2) (2014) 174200.

[26] V. G. Sears, S. M. Bleay, H. L. Bandey, et al. A Methodology for Finger Mark Research. Sci. Justice.52 (2012) 145-160.

[27] Home Office, Fingermark Visualisation Manual, (2014).

[28] C. Wallace-Kunkel, C. Lennard, M. Stoilovic, and C. Roux, Optimisation and Evaluation of 1,2-Indanedione for use as a Fingerprint Reagent and its Application to Real Samples, Forens. Sci. Int. 168(1) (2007) 14-26.

[29] C. Jensen, Ellen. Quantitative Analysis of Histological Staining and Fluorescence Using Image, The Anatomical Record, 296 (3) (2013) 378-381. 